\title{
Synthesis of platencin core structures via twist-brendane
}

\author{
Faiz Ahmed Khan, *a and Basavaraj M. Budanur ${ }^{b}$ \\ ${ }^{a}$ Department of Chemistry, Indian Institute of Technology Hyderabad, Ordnance Factory estate, \\ Yeddumailaram-502205, India \\ ${ }^{b}$ Department of Chemistry, Indian Institute of Technology Kanpur, Kanpur-208016, India \\ E-mail:faiz@,iith.ac.in
}

DOI: http://dx.doi.org/10.3998/ark.5550190.p009.333

\begin{abstract}
The formation of a twist-brendane via intramolecular enolate alkylation is described. Conversion of bicyclo[2.2.1]heptane scaffold present in this twist-brendane through a Grob-type fragmentation to unravel a functionalized bicyclo[2.2.2] system which contains all the necessary carbon atoms of the lipophilic core structure of nor-platencin, a platencin analogue is presented. Synthesis of core structure of platencin was also accomplished by extending this strategy to a starting material possessing a surrogate for the exocyclic methylene group.
\end{abstract}

Keywords: Enones, Grob-type fragmentation, intramolecular enolate alkylation, twist-brendane, platencin

\section{Introduction}

Intramolecular enolate alkylation has been a key step for stereoselective construction of cycloalkanes in the total synthesis of natural products of modest complexity, ${ }^{1-4}$ and in the synthesis of strain free tricyclononane like twist-brendane. ${ }^{5-8}$ The synthesis of natural products involving the Grob fragmentation reaction, a reliable synthetic tool for the cleavage of $\mathrm{C}-\mathrm{C}$ sigma bond leading to useful building blocks, as a key step has been gaining much attention in recent past due to its high efficiency and stereoselectivity. ${ }^{9-13}$ 


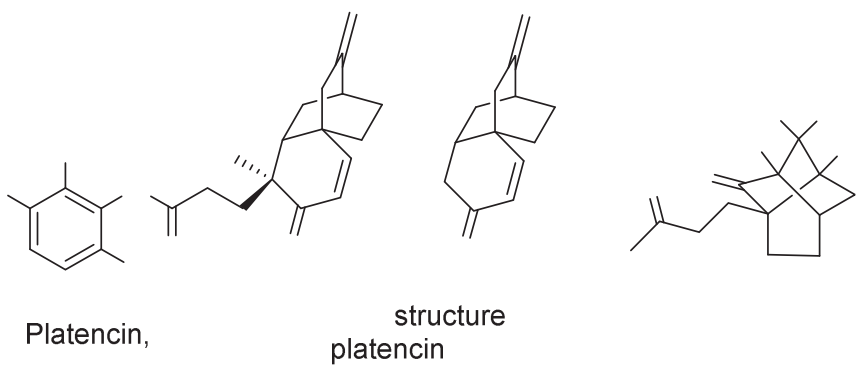

Figure 1. Molecular Structure of Platencin (1), Core Structure (2) of Platencin. Twist-brendane Derivative (5).

As a novel potent antibiotic, platencin ${ }^{14,15}$ inhibits two proteins essential for bacterial fatty acid biosynthesis, $\beta$-ketoacyl carrier protein synthase II (FabF) and III (FabH) with similar potency. Owing to their interesting novel chemical scaffold and biological activity as antibacterial agents platencin and its congeners ${ }^{16}$ have attracted widespread attention amongst synthetic chemists since their discovery with prospect that these would be used as lead compounds for the development of a valuable class of antibiotics. Although platencin shows the potent antibacterial activity it suffers from the poor in vivo efficacy that is attributed to its rapid clearance from tissues. ${ }^{16,17}$ So the synthesis of new potent analogues of platencin with improved potency and pharmacokinetic properties suitable for clinical trials is in high demand. ${ }^{17}$

Platencin core structure constitutes tricyclic system with a bicyclic octane ring having exomethylene group, fused with a cyclohexenone ring. Many synthetic strategies have been developed for the construction of platencin core structure involving key steps like homoallyl radical rearrangement of bicyclo[3.2.1] octane to bicyclo[2.2.2] octane, ${ }^{18-22}$ intramolecular DielsAlder reaction, ${ }^{22-24}$ intramolecular Michael addition, ${ }^{25}$ Michael addition followed by aldol condensation, ${ }^{26}$ ring closing metathesis reaction, ${ }^{27,28}$ pinacol coupling reaction, ${ }^{29}$ radical cyclization reactions $^{30-33}$ and intramolecular aldol reaction. ${ }^{34}$

Although nor-platencin is less potent than its parent molecule, but serves as a convenient target as it lacks the acid-sensitive exo-methylene group present in platencin which is also responsible for the decrease in the metabolic stability of platencin. ${ }^{35}$ In this paper we report synthesis of platencin core structures which features the construction of tricyclic core via a twistbrendane derivative, followed by Grob-type fragmentation and Robinson annulation.

\section{Results and Discussion}

During the course of our studies on base mediated bridgehead elimination and substitution reactions, ${ }^{36}$ we observed the formation of a twist-brendane derivative 5 through intramolecular enolate alkylation in 70\% yield along with the originally intended product 6 (yield 17\%) from 4 (Scheme 1). 


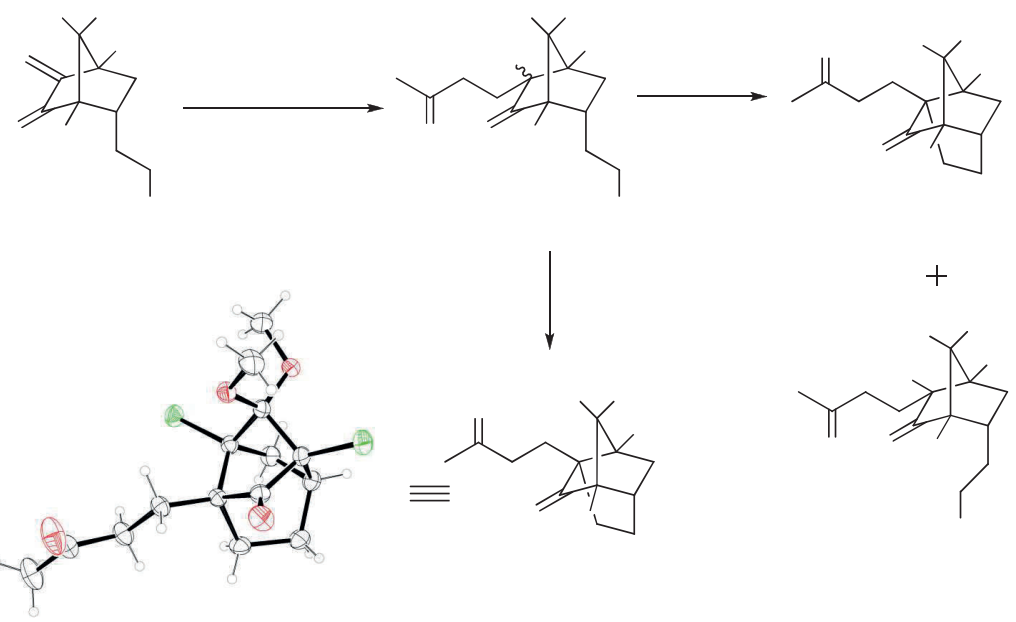

Scheme 1. Synthesis of Twist-brendane Derivative 5.

Synthesis of the parent twist-brendane $e^{5}$ has been described in the literature by intramolecular enolate alkylation using $\mathrm{NaH}$ in $\mathrm{DMF}$ at $60{ }^{\circ} \mathrm{C}$ followed by deoxygenation. We have also adopted the same protocol, but with slight modification wherein THF was used instead of DMF, to avoid the side product $\mathbf{6}$ and observed smooth formation of twist-brendane $\mathbf{5}$ without any side products. The complete sequence involved Michael addition of acetone to the enone 3 to give intermediate 4 which on exposure to $\mathrm{NaH}$ in THF at $60{ }^{\circ} \mathrm{C}$ provided the twist-brendane 5 in $89 \%$ yield (Scheme 1). The structure of twist-brendane was unequivocally proved by single crystal Xray analysis (Scheme 1). Compared to the parent twist-brendane, compound $\mathbf{5}$ is equipped with maneuverable functional groups such as a ketal moiety at C-7 and a suitably positioned keto group for the execution of Grob-type fragmentation ${ }^{12,13}$ to unravel a useful bicyclo[2.2.2] octane derivative.

As anticipated, the Grob-type fragmentation of 5 with pTSA in toluene afforded a separable mixture of bicyclo[2.2.2] octane derivative 7 (Scheme 2). A closely related compound to 7, having exo-methylene group sans the chloro and ester substitutions has been reported for the synthesis of platencin core. ${ }^{33}$ Our attempts to cyclize 7 via Robinson annulation using $\mathrm{NaOH} / \mathrm{EtOH}$ (or $\mathrm{MeOH}$ ) even at reflux conditions failed, yielding complex mixtures. The presence of chlorine substituents might be responsible for the observed complications. In this context, we initially carried out the hydrodehalogenation reaction of the mixture 7 using $n \mathrm{BuSnH} / \mathrm{AIBN}$ which yielded a complex mixture. However, treatment of 7 with zinc dust in acetic acid at room temperature furnished the diketone $\mathbf{8}$ as a single diastereomer (Scheme 2). 

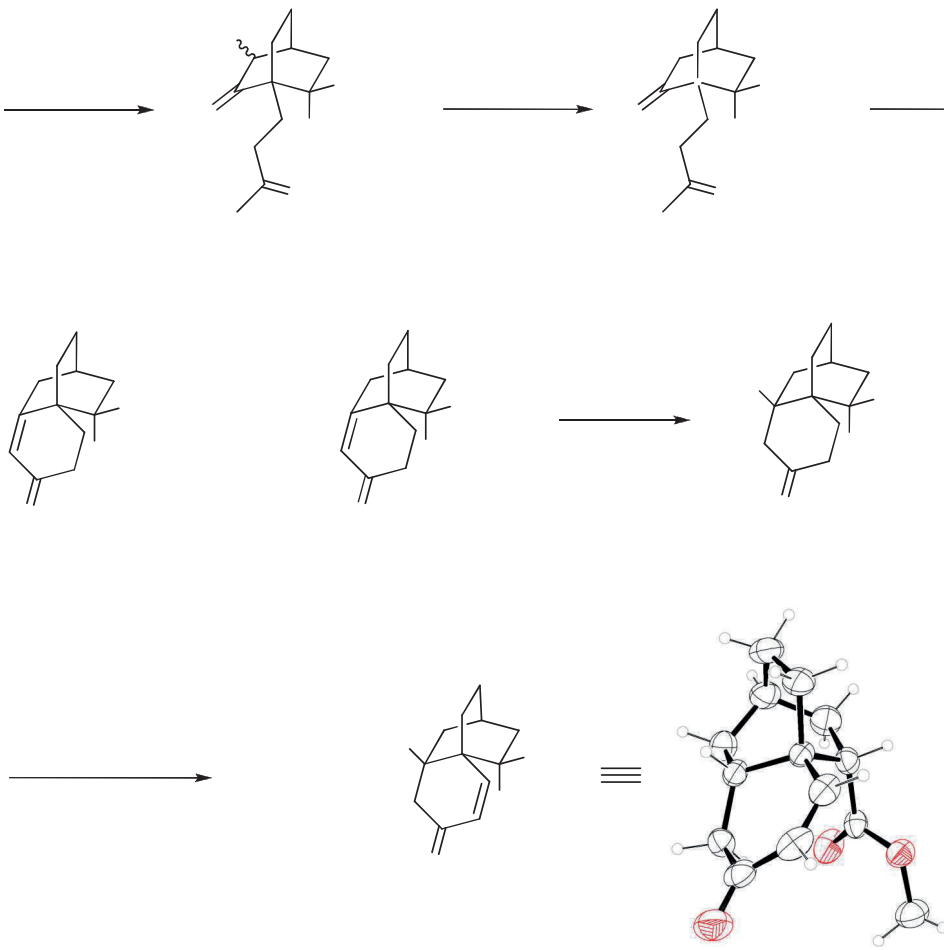

Scheme 2. Synthesis of nor-platencin skeleton.

Having the diketo ester $\mathbf{8}$ in hand, our next task was to convert it to tricyclic enone 9. This was achieved by refluxing 8 in $\mathrm{NaOH} / \mathrm{MeOH}$ for $12 \mathrm{~h}$ followed by diazomethane workup which provided a separable mixture of diastereomers $\mathbf{9 a} / \mathbf{9 b}$ in 1:1 exo/endo ratio of methyl ester (Scheme 2). Reduction enone 9a was carried out using Raney nickel ${ }^{33,37}$ in THF to obtain the keto ester 10 as a single diastereomer in $83 \%$ yield. Several two-step protocols are available in the literature for the conversion of ketone to enone moiety. Silylation followed by 2iodoxybenzoic acid $(\mathrm{IBX})^{38}$ oxidation is a well practiced method in the synthesis of platencin. ${ }^{22,23,30}$ However, in our case Nicolaou's ${ }^{39}$ one-step protocol furnished the desired compound 11 when ketoester 10 was treated with IBX in toluene/DMSO at $65{ }^{\circ} \mathrm{C}$ along with a minor product 9a (Scheme 2). Structure of $\mathbf{1 1}$ was confirmed by single crystal structure X-ray analysis (Scheme 2).

Next, we planned for the synthesis of the core structure of platencin incorporating a keto functionality and adopted similar reaction sequences of the synthesis of core structure of norplatencin. Synthesis commenced with bromination (Scheme 3). Our initial attempts for bromination at the $\alpha$-methyl group of ketone 18 with NBS in THF, ${ }^{40} \mathrm{NBS} / \mathrm{TMSOTf}$ in $\mathrm{CH}_{3} \mathrm{CN},{ }^{41}$ $\mathrm{NBS} / \mathrm{DBU}$ in $\mathrm{CH}_{3} \mathrm{CN},{ }^{42}$ and NBS/AIBN in $\mathrm{CCl}_{4}{ }^{43}$ were sluggish. Nevertheless, conventional brominating agent, $\mathrm{Br}_{2}$ in $\mathrm{MeOH}^{44}$ (at $0{ }^{\circ} \mathrm{C} \rightarrow \mathrm{rt}$ ), provided the bromination product in good yield. Protection of ketone using pTSA in refluxing toluene delivered compound 19 in $79 \%$ yield. On exposure to $\mathrm{Ru}-\mathrm{LDH} / \mathrm{NaIO}_{4}-\mathrm{NaHCO}_{3}{ }^{45-47}$ the intermediate 19 provided diketone $\mathbf{1 7} \mathrm{in}$ 
excellent yield. Subjecting this to Wittig reaction gave enone 16 in 97\% yield. Michael addition of enone 16 with acetone using $\mathrm{NaOH}$ (aq) gave intermediate 20 in near quantitative yield (Scheme 3). NaH mediated intramolecular enolate alkylation proceeded as expected to provide twist-brendane $\mathbf{1 5}$.

The conversion of twist-brendane to bicyclo[2.2.2] octane 21 was easily achieved through a smooth Grob-type fragmentation by treatment of 15 with pTSA in toluene at $80{ }^{\circ} \mathrm{C}$ (Scheme 3 ). Hydrodechlorination with zinc dust in $\mathrm{AcOH}$ gave diketone 14. Robinson annulation of 14 using $\mathrm{NaOH}$ in $\mathrm{MeOH}$ at reflux temperature afforded tricyclic enone 22 in 4:1 exo/endo ratio, as determined from ${ }^{1} \mathrm{H}$ NMR. Deprotection of ketal group with $6 \mathrm{~N} \mathrm{HCl}$ at room temperature gave $\mathbf{1 3}$ in good yield. Regioselective Wittig reaction of unconjugated ketone group in $\mathbf{1 3}$ to exomethylene proceeded smoothly at $-78{ }^{\circ} \mathrm{C}$ to give dienone 12 in $72 \%$ yield (Scheme 3 ). As Wittig reaction was carried out under strong basic condition one can expect the abstraction of proton adjacent to the ester group. Once the carbanion is formed the bulky ester group would prefer relatively free room exo position and hence the conversion of endo isomer to exo occurs, which can be accounted for the high diastereoselectivity (exo:endo 10:1) in the Wittig reaction.
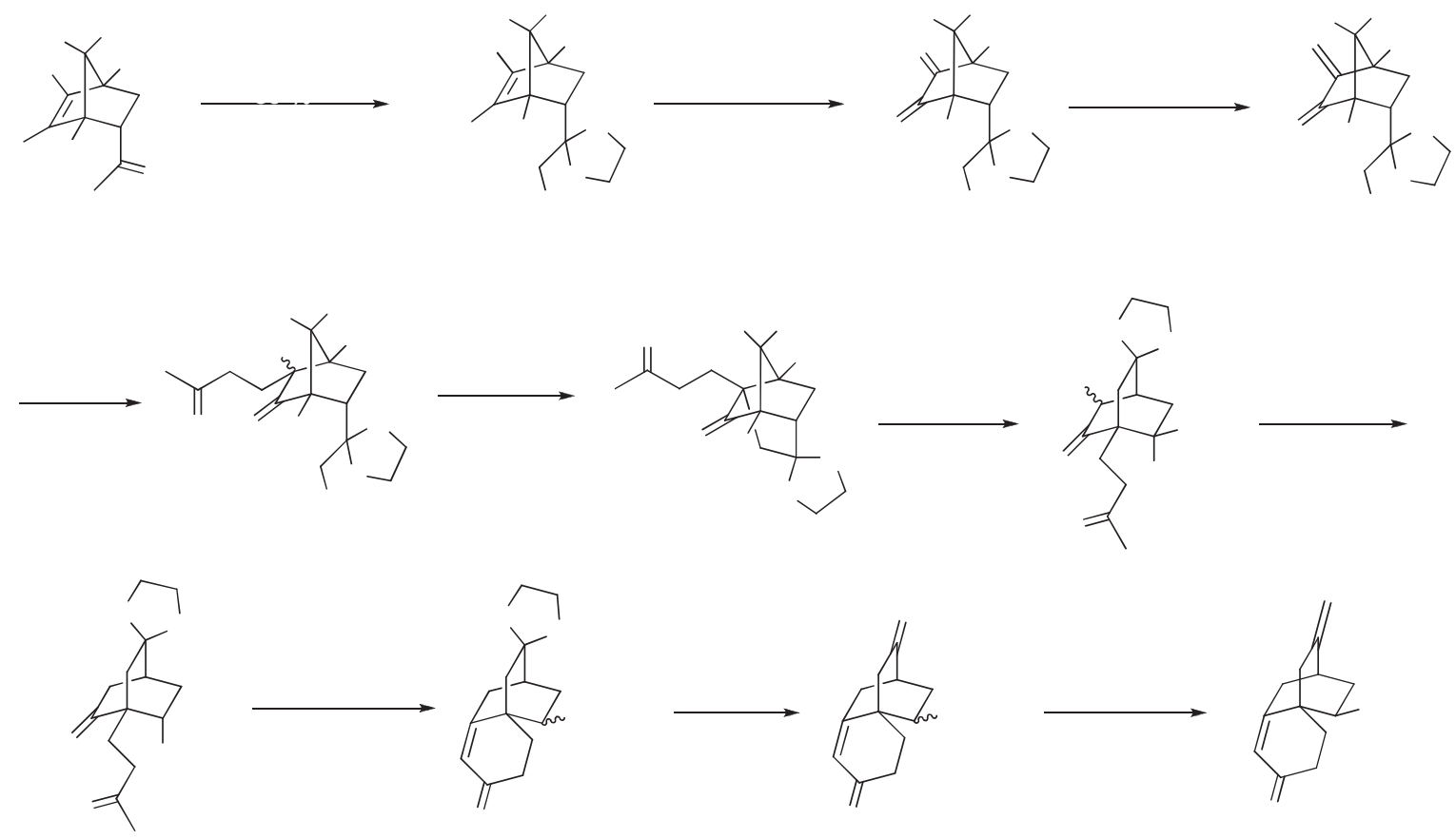

Scheme 3: Synthesis of platencin core.

The stereochemistry of the major component in $\mathbf{1 3}$ was arrived at from 2D NMR data analysis of the mixture. Based on the correlations of proton signals at $\delta 2.44(\mathrm{~m}, 1 \mathrm{H})$ and 2.36 $(\mathrm{m}, 1 \mathrm{H})\left(\mathrm{CH}_{2}\right.$ group adjacent to $\mathrm{CO}$ in the bicyclooctane ring) with carbon at $\delta 210.9$ in $\mathrm{HMBC}$, 
these were assigned to methylene group attached to ketone. Similarly, methine group attached to methyl ester was deduced by correlation between proton at $\delta 2.87-2.79(\mathrm{~m}, 1 \mathrm{H})$ and carbon at $\delta$ 174.3 , which also shows correlation with methoxy group at $\delta 3.72$. The absence of correlation between the protons at $\delta 2.52-2.34$ and $\delta 2.87-2.79$ in NOESY confirms that the methine proton is endo and the ester group is exo in compound 13 and also 12. As expected, during the strongly basic Witting reaction conditions, further isomerization of $\mathbf{1 3}$ resulted in substantial enhancement in exo/endo ratio from 4:1 in $\mathbf{1 3}$ to $10: 1$ in $\mathbf{1 2}$.

\section{Conclusions}

In conclusion, we have synthesized functionalized twist-brendane derivatives through intramolecular enolate alkylation. We have demonstrated a strategy for the conversion of bicyclo[2.2.1] heptane to bicyclo[2.2.2]octane derivative through the formation twist-brendane followed by Grob-type fragmentation. The fragmented products were carried forward for the synthesis of the core structures of both nor-platencin and platencin. Structures and stereochemistry of some of the intermediates were confirmed by single crystal X-ray analysis and 2D NMR analysis.

\section{Experimental Section}

General. Unless otherwise specified, all reactions were carried out in oven dried glassware, under argon atmosphere. Melting points were determined on an electrothermal melting point apparatus and are uncorrected. THF was dried by refluxing over sodium metal. Sodium methoxide was prepared from sodium and methanol. Zinc was activated by $10 \% \mathrm{HCl}$ before use. DMSO was distilled from anhydrous $\mathrm{CaSO}_{4} /$ calcium hydride. Potassium tert-butoxide was sublimed before use. ${ }^{1} \mathrm{H}$ and proton decoupled ${ }^{13} \mathrm{C}$ NMR spectra were recorded in 400 and 100 $\mathrm{MHz}$, respectively. The NMR samples were prepared by dissolving in $\mathrm{CDCl}_{3}$, chemical shifts $(\delta$ $\mathrm{ppm})$ are reported with reference to either internal standard tetramethylsilane, TMS $\left(\delta_{\mathrm{H}}=0.00\right.$ ppm) or $\mathrm{CHCl}_{3}\left(\delta_{\mathrm{H}}=7.27 \mathrm{ppm}\right)$ for ${ }^{1} \mathrm{H}$ NMR and $\mathrm{CHCl}_{3}\left[\delta_{\mathrm{C}}=77.00 \mathrm{ppm}\right.$ (central line of the triplet)] chemical shifts $(\delta \mathrm{ppm})$ for ${ }^{13} \mathrm{C}$ NMR. The multiplicity are reported as follows $\mathrm{s}=$ singlet, $\mathrm{d}=$ doublet, $\mathrm{dd}=$ double doublet, $\mathrm{t}=$ triplet, $\mathrm{dt}=$ double triplet, $\mathrm{td}=$ triple doublet, $\mathrm{q}=$ quartet, $\mathrm{br}=$ broad $\mathrm{m}=$ multiplet and the coupling constants were in Hz. HRMS was performed using a Q-TOF multimode source.

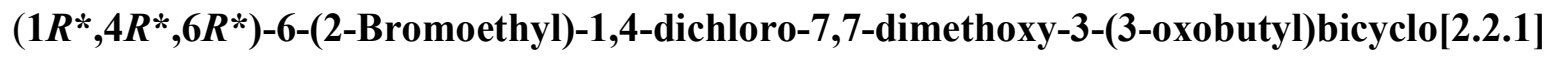
heptan-2-one 4. To a stirred solution of enone $\mathbf{3}^{36}(5 \mathrm{~g}, 13.96 \mathrm{mmol})$ in acetone $(140 \mathrm{~mL})$ was added aqueous sodium hydroxide solution $(8.3 \mathrm{~mL}, 16.7 \mathrm{mmol}, 2 \mathrm{M})$ at $0{ }^{\circ} \mathrm{C}$ for $5 \mathrm{~min}$. After being stirred for $1 \mathrm{~h}, 5 \mathrm{ml}$ of $10 \% \mathrm{HCl}$ was added, solvent was evaporated under reduced 
pressure and diluted with EtOAc $(150 \mathrm{~mL})$, organic phase was separated aqueous phase was extracted with EtOAc $(200 \mathrm{ml} \times 2)$ combined organic phases were washed with water $(200 \mathrm{~mL})$, brine $(100 \mathrm{~mL})$, dried over $\mathrm{Na}_{2} \mathrm{SO}_{4}$ and concentrated in vacuo. The resulting crude was purified over silica gel column chromatography (eluent: EtOAc-Hexane $=1: 5$ ) to afford Michael product $4(5.67 \mathrm{~g}, 98 \%)$ as a colorless liquid. ${ }^{1} \mathrm{H}$ NMR $\left(400 \mathrm{MHz}, \mathrm{CDCl}_{3}\right) \delta 3.69(\mathrm{~s}, 3 \mathrm{H}), 3.66(\mathrm{~s}, 3 \mathrm{H}$, minor isomer), $3.60(\mathrm{~s}, 3 \mathrm{H}), 3.58(\mathrm{~s}, 3 \mathrm{H}$, minor isomer), 3.47-3.40 $(\mathrm{m}, 1 \mathrm{H}), 3.38-3.30(\mathrm{~m}, 1 \mathrm{H})$, 2.99 (ddd, $J 5.9,8.8,18.6 \mathrm{~Hz}, 1 \mathrm{H}), 2.86$ (ddd, $J 2.7,5.0,7.5 \mathrm{~Hz}, 1 \mathrm{H}), 2.79-2.73(\mathrm{~m}, 1 \mathrm{H}), 2.73-$ $2.63(\mathrm{~m}, 2 \mathrm{H}), 2.61-2.52(\mathrm{~m}, 1 \mathrm{H}), 2.19(\mathrm{~s}, 3 \mathrm{H}), 2.17$ (s, 3H, minor isomer), 2.08-1.75 (m, 5H), 1.51-1.39 (m, 1H). ${ }^{13} \mathrm{C}$ NMR $\left(100 \mathrm{MHz}, \mathrm{CDCl}_{3}\right) \delta 207.3,202.4,104.7,80.4,69.3,55.7,51.8$, 51.7, 41.4, 40.4, 36.1, 32.6, 30.4, 30.0, 18.2. HRMS (ESI): $\mathrm{m} / z$ calcd for $\mathrm{C}_{15} \mathrm{H}_{25} \mathrm{BrCl}_{2} \mathrm{NO}_{4}[\mathrm{M}+$ $\left.\mathrm{NH}_{4}\right]^{+}$432.0344; found: 432.0298 .

Twist-brendane Derivative 5. To a stirred solution of $4(5 \mathrm{~g}, 12.01 \mathrm{mmol})$ in THF $(150 \mathrm{~mL})$ was added sodium hydride (625 mg, $15.61 \mathrm{mmol}, 60 \%$ in mineral oil) in two portions at $0{ }^{\circ} \mathrm{C}$ and allowed to warm to $\mathrm{rt}$ and then heated at $60{ }^{\circ} \mathrm{C}$. After completion of starting material (monitored by tlc) $50 \mathrm{~mL}$ of water was added at $0{ }^{\circ} \mathrm{C}$, solvent was evaporated under reduced pressure diluted with EtOAc $(200 \mathrm{ml})$, organic phase was separated aqueous phase was extracted with $\operatorname{EtOAc}(150 \mathrm{ml} \mathrm{x} \mathrm{2)}$, combined organic phases were washed with water $(200 \mathrm{~mL})$, brine $(100$ $\mathrm{mL}$ ), dried over $\mathrm{Na}_{2} \mathrm{SO}_{4}$ and concentrated in vacuo. The resulting crude was purified over silica gel column chromatography (eluent: EtOAc-Hexane $=1: 5)$ to afford twist-brendane $\mathbf{5}(3.58 \mathrm{~g}$, $89 \%$ ) as a colorless crystalline solid (solvent: acetonitrile). mp: $142-144{ }^{\circ} \mathrm{C} .{ }^{1} \mathrm{H} \mathrm{NMR}(400 \mathrm{MHz}$, $\left.\mathrm{CDCl}_{3}\right) \delta 3.61(\mathrm{~s}, 3 \mathrm{H}), 3.42(\mathrm{~s}, 3 \mathrm{H}), 2.78-2.57(\mathrm{~m}, 3 \mathrm{H}), 2.49(\mathrm{td}, J 2.2,4.4 \mathrm{~Hz}, 1 \mathrm{H}), 2.17-2.06$ $(\mathrm{m}, 2 \mathrm{H}), 2.13(\mathrm{~s}, 3 \mathrm{H}), 2.02-1.91(\mathrm{~m}, 1 \mathrm{H}), 1.85(\mathrm{~d}, J 11.2 \mathrm{~Hz}, 1 \mathrm{H}), 1.73-1.62(\mathrm{~m}, 3 \mathrm{H}) .{ }^{13} \mathrm{C} \mathrm{NMR}$ $\left(100 \mathrm{MHz}, \mathrm{CDCl}_{3}\right) \delta 208.3,204.5,104.5,78.1,73.3,56.6,51.6,51.1,47.9,39.1,36.73,31.2$, 29.9, 24.6, 24.3. HRMS (ESI): $m / z$ calcd for $\mathrm{C}_{15} \mathrm{H}_{24} \mathrm{Cl}_{2} \mathrm{NO}_{4}\left[\mathrm{M}+\mathrm{NH}_{4}\right]^{+} 352.1082$; found: 352.1076 .

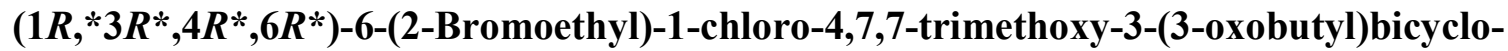

[2.2.1]heptan-2-one6. To a stirred solution of $4(210 \mathrm{mg}, 0.50 \mathrm{mmol})$ in methanol $(2.5 \mathrm{~mL})$ was added sodium methoxide ( $81 \mathrm{mg}, 1.5 \mathrm{mmol}$ ) at room temperature and slowly allowed to warm to reflux temperature. After being refluxed for $4 \mathrm{~h}$, reaction mixture cooled to $0{ }^{\circ} \mathrm{C}, 1 \mathrm{~mL}$ of water was added diluted with EtOAc $(40 \mathrm{~mL})$, organic phase was separated, aqueous phase was extracted with EtOAc (30 mL x 3) combined organic phases were washed with water $(40 \mathrm{~mL})$, brine $(20 \mathrm{~mL})$, dried over $\mathrm{Na}_{2} \mathrm{SO}_{4}$ and evaporated under reduced pressure. The resulting residue was purified over silica gel column chromatography (10-20\% EtOAc in hexane) to give compounds 5 (117 mg, 70\% colorless crystalline solid (needles), crystallized from acetonitrile) and 6 (35 mg, 17\%, colorless liquid). Data for compound 6: ${ }^{1} \mathrm{H}$ NMR (400 MHz, $\left.\mathrm{CDCl}_{3}\right) \delta 3.65-$ $3.59(\mathrm{~m}, 1 \mathrm{H}), 3.62(\mathrm{~s}, 3 \mathrm{H}), 3.59-3.50(\mathrm{~m}, 1 \mathrm{H}), 3.55(\mathrm{~s}, 3 \mathrm{H}), 3.51(\mathrm{~s}, 3 \mathrm{H}), 2.93-2.84(\mathrm{~m}, 1 \mathrm{H})$, 2.79-2.64 (m, 3H), 2.64-2.54 (m, 1H), $2.16(\mathrm{~s}, 3 \mathrm{H}), 2.01-1.91(\mathrm{~m}, 1 \mathrm{H}), 1.79(\mathrm{q}, J 7.7 \mathrm{~Hz}, 2 \mathrm{H})$, $1.52(\mathrm{dd}, J 3.9,12.2 \mathrm{~Hz}, 1 \mathrm{H}), 1.40-1.32(\mathrm{~m}, 1 \mathrm{H}) .{ }^{13} \mathrm{C} \mathrm{NMR}\left(100 \mathrm{MHz}, \mathrm{CDCl}_{3}\right) \delta 207.8,203.7$, $106.1,83.5,80.3,53.4,52.6,51.01,51.00,42.7,41.5,38.1,32.6,30.1,27.6,18.3$. IR (neat) 
2927, 1762, 1713, 1451, 1264, 1212, 1164, 1096, 1033, $986 \mathrm{~cm}^{-1}$; HRMS (ESI): $\mathrm{m} / z$ calcd for $\mathrm{C}_{16} \mathrm{H}_{25} \mathrm{BrClO}_{5}[\mathrm{M}+\mathrm{H}]^{+}$411.0574; found: 411.0573 .

$\left(1 R^{*}, 2 R^{*}, 4 S^{*}\right)$-Methyl 2,5-dichloro-6-oxo-1-(3-oxobutyl)bicyclo[2.2.2]octane-2-carboxylate 7: To a stirred solution of $5(500 \mathrm{mg}, 1.49 \mathrm{mmol})$ in toluene $(15 \mathrm{~mL})$ was added pTSA $(368 \mathrm{mg}$, $1.93 \mathrm{mmol}$ ) at $\mathrm{rt}$ and then slowly heated at $80{ }^{\circ} \mathrm{C}$. After being heated for $5 \mathrm{~h}$ solvent was evaporated under reduced pressure, the residue was partition between EtOAc $(80 \mathrm{~mL})$ and water $(25 \mathrm{~mL})$, organic phase was separated aqueous phase was extracted with EtOAc $(75 \mathrm{~mL} \times 2)$ combined organic phases were washed with aq. $\mathrm{NaHCO}_{3}$ solution $(30 \mathrm{~mL})$, water $(80 \mathrm{~mL} \times 2)$, brine $(40 \mathrm{~mL})$, dried over $\mathrm{Na}_{2} \mathrm{SO}_{4}$ and evaporated to dryness. The resulting crude was purified over silica gel column chromatography (eluent: EtOAc-Hexane $=1: 4$ ) to afford fragmented products 7 (418 mg, 88\%) in 1:1 mixture of separable diastereomers as pale yellow solids (needles- crystallized from acetonitrile). Data for less polar compound (7a); mp: 76-78 ${ }^{\circ} \mathrm{C}$ (A); $\mathrm{R}_{f}=0.6\left(15 \%\right.$ EtOAc in hexane). ${ }^{1} \mathrm{H}$ NMR $\left(400 \mathrm{MHz}, \mathrm{CDCl}_{3}\right) \delta 4.31(\mathrm{~d}, J 1.5 \mathrm{~Hz}, 1 \mathrm{H}), 3.78(\mathrm{~s}$, $3 \mathrm{H}), 2.69-2.61(\mathrm{~m}, 1 \mathrm{H}), 2.61-2.50(\mathrm{~m}, 2 \mathrm{H}), 2.45(\mathrm{~d}, J 2.9 \mathrm{~Hz}, 1 \mathrm{H}), 2.39-2.27(\mathrm{~m}, 1 \mathrm{H}), 2.27-2.14$ $(\mathrm{m}, 2 \mathrm{H}), 2.12(\mathrm{~s}, 3 \mathrm{H}), 1.92-1.78(\mathrm{~m}, 2 \mathrm{H}), 1.77-1.59(\mathrm{~m}, 2 \mathrm{H}) ;{ }^{13} \mathrm{C} \mathrm{NMR}\left(100 \mathrm{MHz}, \mathrm{CDCl}_{3}\right) \delta$ 207.5, 204.3, 171.5, 72.4, 59.2, 54.0, 53.4, 44.2, 38.1, 34.3, 29.9, 23.3, 23.2, 17.9. HRMS (ESI): $m / z$ calcd for $\mathrm{C}_{14} \mathrm{H}_{22} \mathrm{Cl}_{2} \mathrm{NO}_{4}\left[\mathrm{M}+\mathrm{NH}_{4}\right]^{+} 338.0926$; found: 338.0908 . Data for polar compound (7b): mp: 80-82 ${ }^{\circ} \mathrm{C} ; \mathrm{R}_{f}=0.6$ (15\% EtOAc in hexane); ${ }^{1} \mathrm{H}$ NMR (400 MHz, $\left.\mathrm{CDCl}_{3}\right) \delta 4.25$ (t, $J$ $2.0 \mathrm{~Hz}, 1 \mathrm{H}), 3.81-3.74(\mathrm{~m}, 3 \mathrm{H}), 3.04(\mathrm{td}, J 2.1,15.3 \mathrm{~Hz}, 1 \mathrm{H}), 2.56-2.47(\mathrm{~m}, 1 \mathrm{H}), 2.46-2.40(\mathrm{~m}$, $1 \mathrm{H}), 2.33(\mathrm{dd}, J 2.4,3.9 \mathrm{~Hz}, 1 \mathrm{H}), 2.31-2.27(\mathrm{~m}, 1 \mathrm{H}), 2.20-2.13(\mathrm{~m}, 2 \mathrm{H}), 2.12(\mathrm{~s}, 3 \mathrm{H}), 1.99-1.87$ $(\mathrm{m}, 1 \mathrm{H}), 1.81(\mathrm{ddd}, J 3.7,6.1,9.8 \mathrm{~Hz}, 2 \mathrm{H}), 1.63-1.54(\mathrm{~m}, 1 \mathrm{H}) .{ }^{13} \mathrm{C} \mathrm{NMR}\left(100 \mathrm{MHz}, \mathrm{CDCl}_{3}\right) \delta$ 207.4, 203.9, 170.2, 74.1, 59.1, 53.7, 52.9, 38.5, 38.0, 35.1, 29.8, 22.8, 22.2, 22.0. HRMS (ESI): $\mathrm{m} / z$ calcd for $\mathrm{C}_{14} \mathrm{H}_{19} \mathrm{Cl}_{2} \mathrm{O}_{4}[\mathrm{M}+\mathrm{H}]^{+} 321.0660$; found: 321.0662 .

$\left(1 S^{*}, 2 S^{*}, 4 S^{*}\right)$-Methyl 6-oxo-1-(3-oxobutyl)bicyclo[2.2.2]octane-2-carboxylate 8. To a stirred solution of 7 (290 mg, $0.9 \mathrm{mmol})$ in AcOH $(5 \mathrm{~mL})$ was added zinc dust (236 mg, $3.61 \mathrm{mmol})$ at room temperature. After being stirred for $6 \mathrm{~h}$ (reaction monitored by TLC), reaction mixture was diluted with EtOAc $(50 \mathrm{~mL})$ and filtered through cotton washed with EtOAc $(80 \mathrm{~mL})$. The filtrate was washed with saturated $\mathrm{NaHCO}_{3}$ solution $(25 \mathrm{~mL})$, water $(30 \mathrm{~mL}$ x 2), brine $(20 \mathrm{~mL})$, dried over $\mathrm{Na}_{2} \mathrm{SO}_{4}$ and concentrated under reduced pressure. Silica gel column (eluent:Ethyl acetate- hexane $=1: 3)$ purification of the resulting crude afforded diketo ester $\mathbf{8}(185 \mathrm{~g}, 82 \%)$ as pale yellow liquid; $\mathrm{R}_{f}=0.5$ (30\% EtOAc in hexane). ${ }^{1} \mathrm{H}$ NMR $\left(400 \mathrm{MHz}, \mathrm{CDCl}_{3}\right) \delta 3.69-3.59(\mathrm{~m}$, $3 \mathrm{H}), 2.81(\mathrm{dd}, J 5.4,11.2 \mathrm{~Hz}, 1 \mathrm{H}), 2.58-2.47(\mathrm{~m}, 1 \mathrm{H}), 2.47-2.34(\mathrm{~m}, 2 \mathrm{H}), 2.31(\mathrm{t}, J 2.7 \mathrm{~Hz}, 1 \mathrm{H})$, 2.28-2.19 (m, 1H), 2.14 (s, 3H), 2.07 (tdd, $J 2.8,11.1,13.8 \mathrm{~Hz}, 1 \mathrm{H}), 1.88-1.77$ (m, 2H), 1.761.61 (m, 3H), 1.61-1.49 (m, 2H); ). $\left.{ }^{13} \mathrm{C} \mathrm{NMR} \mathrm{(100} \mathrm{MHz,} \mathrm{CDCl}_{3}\right) \delta 213.4,208.4,175.1,52.0$, 46.4, 46.3, 44.3, 38.2, 30.2, 29.8, 27.1, 26.8, 25.6, 24.6; IR (neat) 2945, 2873, 1719 (br.), 1440, 1360, 1165, $1094 \mathrm{~cm}^{-1}$; HRMS (ESI): $m / z$ calcd for $\mathrm{C}_{14} \mathrm{H}_{24} \mathrm{NO}_{4}[\mathrm{M}+\mathrm{H}]^{+} 270.1705$; found: 270.1688 .

Enone 9. To a stirred solution of $8(180 \mathrm{mg}, 0.71 \mathrm{mmol})$ in $\mathrm{MeOH}(32 \mathrm{~mL})$ was added sodium hydroxide $(200 \mathrm{mg}, 5 \mathrm{mmol})$ at room temperature and then slowly heated at reflux temperature. After being refluxed for $15 \mathrm{~h}$ (monitored by TLC), $3 \mathrm{~mL}$ of $10 \% \mathrm{HCl}$ was added at $0{ }^{\circ} \mathrm{C}$, solvent 
was evaporated under reduced pressure, the residue was partition between EtOAc $(50 \mathrm{~mL})$ and water $(10 \mathrm{~mL})$, organic phase was separated and the aqueous phase was extracted with EtOAc $(50 \mathrm{~mL} \times 3)$ combined organic phases were washed with water $(30 \mathrm{~mL} \times 2)$, brine $(20 \mathrm{~mL})$, dried over $\mathrm{Na}_{2} \mathrm{SO}_{4}$ and evaporated dryness. The resulting crude was dissolved in $\mathrm{MeOH}(3 \mathrm{~mL})$ cooled to $0{ }^{\circ} \mathrm{C}$, and then a solution of $\mathrm{CH}_{2} \mathrm{~N}_{2}$ in ether was added until yellow color persist. A pinch $\mathrm{AcOH}$ was added to quench excess of diazomethane. Reaction mixture was concentrated under reduced pressure and the resulting crude was purified over silica gel column chromatography (eluent:Ethyl acetate- hexane= 1: 4) to give enone $9(122 \mathrm{mg}, 73 \%)$ in 1:1 mixture of separable diastereomers as pale yellow liquids. Data for compound $9 \mathrm{a} ; \mathrm{R}_{f}=0.65$ (30\% EtOAc in hexane). ${ }^{1} \mathrm{H}$ NMR $\left(400 \mathrm{MHz}, \mathrm{CDCl}_{3}\right) \delta 5.88(\mathrm{t}, J 1.7 \mathrm{~Hz}, 1 \mathrm{H}), 3.71(\mathrm{~s}, 3 \mathrm{H}), 2.78-2.68(\mathrm{~m}, 1 \mathrm{H}), 2.51-2.44$ (m, 2H), 2.45-2.36 (m, 2H), 2.09-1.95 (m, 2H), 1.95-1.89 (m, 1H), 1.89-1.79 (m, 2H), 1.72-1.61 $(\mathrm{m}, 3 \mathrm{H}), 1.64-1.54(\mathrm{~m}, 1 \mathrm{H}) .{ }^{13} \mathrm{C} \mathrm{NMR}\left(100 \mathrm{MHz}, \mathrm{CDCl}_{3}\right) \delta 198.2,174.6,169.2,124.5,51.7$, 43.5, 36.3, 35.6, 33.73, 30.2, 29.6, 25.8, 25.4, 25.2. IR (neat) 2928, 2856, 1723, 1682, 1481, 1392, 1359, 1279, 1194, 1165, $1063 \mathrm{~cm}^{-1}$; HRMS (ESI): $\mathrm{m} / z$ calcd for $\mathrm{C}_{14} \mathrm{H}_{19} \mathrm{O}_{3}[\mathrm{M}+\mathrm{H}]^{+}$ 235.1334; found: 235.1331. Data for compound $\mathbf{9 b}: \mathrm{R}_{f}=0.6$ (30\% EtOAc in hexane). ${ }^{1} \mathrm{H}$ NMR $\left(400 \mathrm{MHz}, \mathrm{CDCl}_{3}\right) \delta 5.94(\mathrm{~s}, 1 \mathrm{H}), 3.66(\mathrm{~s}, 3 \mathrm{H}), 2.73(\mathrm{dd}, J 2.2,18.3 \mathrm{~Hz}, 1 \mathrm{H}), 2.67$ (dd, $J 4.9,10.8$ $\mathrm{Hz}, 1 \mathrm{H}), 2.45(\mathrm{~d}, J 15.7 \mathrm{~Hz}, 1 \mathrm{H}), 2.41-2.34(\mathrm{~m}, 1 \mathrm{H}), 2.26-2.16(\mathrm{~m}, 1 \mathrm{H}), 2.06-1.92(\mathrm{~m}, 3 \mathrm{H}), 1.91-$ $1.81(\mathrm{~m}, 2 \mathrm{H}), 1.74-1.49(\mathrm{~m}, 4 \mathrm{H}) .{ }^{13} \mathrm{C}$ NMR $\left(100 \mathrm{MHz}, \mathrm{CDCl}_{3}\right) \delta 197.9,175.4,168.1,125.6,51.8$, 47.6, 36.6, 36.0, 33.8, 31.9, 30.4, 30.3, 25.3, 25.2; IR (neat) 2924, 2864, 1729, 1680, 1480, 1392, 1194, 1165, $1063 \mathrm{~cm}^{-1}$; HRMS (ESI): $\mathrm{m} / z$ calcd for $\mathrm{C}_{14} \mathrm{H}_{18} \mathrm{O}_{3} \mathrm{Na}[\mathrm{M}+\mathrm{Na}]^{+}$257.1154; found: 257.1151

Keto ester 10. To a stirred solution of 9 a $(30 \mathrm{mg}, 0.128 \mathrm{mmol})$ in THF ( $2 \mathrm{~mL})$ was added Ra-Ni $(3 \times 0.3 \mathrm{~g})$ three times after every $1 \mathrm{~h}$ at room temperature. After being stirred for $10 \mathrm{~h}$, reaction mixture was diluted with EtOAc $(20 \mathrm{~mL})$ filtered through silica pad washed with EtOAc (30 $\mathrm{mL}$ ). The filtrate was concentrated under reduced pressure. The resulting residue was purified over silica gel column chromatography (eluent: Ethyl acetate-hexane $=1: 4$ ) afforded keto ester $10(25 \mathrm{mg}, 83 \%)$ as a colorless liquid. $\mathrm{R}_{f}=0.5$ (15\% EtOAc in hexane). ${ }^{1} \mathrm{H}$ NMR (400 MHz, $\left.\mathrm{CDCl}_{3}\right) \delta 3.70(\mathrm{~s}, 3 \mathrm{H}), 2.77(\mathrm{t}, J 14.2 \mathrm{~Hz}, 1 \mathrm{H}), 2.57(\mathrm{dd}, J 6.6,10.5 \mathrm{~Hz}, 1 \mathrm{H}), 2.29-1.99(\mathrm{~m}, 4 \mathrm{H})$, $1.99-1.75(\mathrm{~m}, 3 \mathrm{H}), 1.75-1.62(\mathrm{~m}, 2 \mathrm{H}), 1.61-1.47(\mathrm{~m}, 4 \mathrm{H}), 1.45-1.43(\mathrm{~m}, 1 \mathrm{H}), 1.34-1.27(\mathrm{~m}$, 1H). ${ }^{13} \mathrm{C} \mathrm{NMR}\left(100 \mathrm{MHz}, \mathrm{CDCl}_{3}\right) \delta 212.6,178.2,52.0,46.1,45.4,38.8,38.4,37.9,35.1,33.9$, 33.6, 31.1, 25.1, 24.3. IR (neat) 2926, 2862, 1725, 1713, 1453, 1434, 1359, 1262, 1193, 1169, 1030, $990 \mathrm{~cm}^{-1}$. HRMS (ESI): $\mathrm{m} / z$ calcd for $\mathrm{C}_{14} \mathrm{H}_{20} \mathrm{O}_{3} \mathrm{H}[\mathrm{M}+\mathrm{H}]^{+} 237.1491$; found: 237.1485 .

Enone 11. To a stirred solution of $10(10 \mathrm{mg}, 0.042 \mathrm{mmol})$ in toluene $(0.8 \mathrm{~m})$ and DMSO $(0.4$ $\mathrm{mL})$ was added IBX $(28 \mathrm{mg}, 0.096 \mathrm{mmol})$ at room temperature and slowly heated at $70{ }^{\circ} \mathrm{C}$. After being stirred for 2 days, reaction mixture was diluted with EtOAc $(20 \mathrm{~mL})$, washed with $5 \%$ $\mathrm{NaHCO}_{3}$ aqueous solution, organic phase was separated, aqueous phase was extracted with EtOAc $(15 \mathrm{~mL} \times 3)$ combined organic phase was washed with water $(15 \mathrm{~mL})$, brine $(10 \mathrm{~mL})$ dried over $\mathrm{Na}_{2} \mathrm{SO}_{4}$ and concentrated in vacuo. The resulting crude was purified over silica gel column chromatography (20\% EtOAc in hexane) to afford compound $\mathbf{1 1}$ (6.4 mg, 70\% yield) as colorless solid (crystalline- crystallized from EtOAc: hexane (1:2)), mp: $44-46{ }^{\circ} \mathrm{C} ; \mathrm{R}_{f}=0.6(20 \%$ 
EtOAc in hexane). ${ }^{1} \mathrm{H}$ NMR $\left(400 \mathrm{MHz}, \mathrm{CDCl}_{3}\right) \delta 6.62(\mathrm{~d}, J 9.8 \mathrm{~Hz}, 1 \mathrm{H}), 5.93(\mathrm{~d}, J 9.8 \mathrm{~Hz}, 1 \mathrm{H})$, $3.58(\mathrm{~s}, 3 \mathrm{H}), 2.66(\mathrm{dd}, J 3.9,11.2 \mathrm{~Hz}, 1 \mathrm{H}), 2.43-2.13(\mathrm{~m}, 4 \mathrm{H}), 2.01-1.84(\mathrm{~m}, 2 \mathrm{H}), 1.81-1.54(\mathrm{~m}$, 4H), 1.54-1.40 (m, 2H). ${ }^{13} \mathrm{C}$ NMR $\left(100 \mathrm{MHz}, \mathrm{CDCl}_{3}\right) \delta 200.4,176.0,155.3,128.1,51.6,45.1$, 41.1, 36.7, 35.6, 35.1, 21.4, 28.4, 24.4, 24.1. IR (neat) 2933, 2866, 1727, 1680, 1452, 1435, 1357, 1257, 1200, 1174, 1074, $923 \mathrm{~cm}^{-1}$. HRMS (ESI): $\mathrm{m} / z$ calcd for $\mathrm{C}_{14} \mathrm{H}_{19} \mathrm{O}_{3}[\mathrm{M}+\mathrm{H}]^{+}$ 235.1334; found: 235.1332

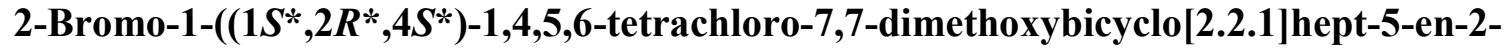

yl)ethanone I. To a stirred solution of Diels-Alder adduct $17(5 \mathrm{~g}, 14.97 \mathrm{mmol})$ in $\mathrm{MeOH}(20$ $\mathrm{mL}$ ) was added bromine $(2.6 \mathrm{~g}, 16.46 \mathrm{mmol})$ at $0{ }^{\circ} \mathrm{C}$ and allowed to warm to room temperature. After being stirred for $8 \mathrm{~h}$ (monitored by tlc) $15 \mathrm{~mL}$ of water was added at $0{ }^{\circ} \mathrm{C}$ and stirred for 1 h. The reaction mixture was diluted with EtOAc $(150 \mathrm{~mL})$, organic phase was separated, aqueous phase was extracted with EtOAc $(100 \mathrm{~mL}$ x 3$)$ combined organic phase was washed with $10 \%$ $\mathrm{Na}_{2} \mathrm{CO}_{3}$ solution $(30 \mathrm{~mL})$, water $(100 \mathrm{~mL}$ x 2$)$, brine $(60 \mathrm{~mL})$, dried over $\mathrm{Na}_{2} \mathrm{SO}_{4}$ and concentrated under reduced pressure. The resulting crude was purified over silica gel column chromatography (3\% EtOAc in hexane) to afford intermediate $\mathbf{I}(5.13 \mathrm{~g}, 83 \%)$ as a colorless liquid, $\mathrm{R}_{f}=0.4\left(5 \%\right.$ EtOAc in hexane). ${ }^{1} \mathrm{H}$ NMR $\left(400 \mathrm{MHz}, \mathrm{CDCl}_{3}\right) \delta 4.20(\mathrm{~d}, J 13.1 \mathrm{~Hz}, 1 \mathrm{H})$, 4.09 (d, J 13.2 Hz, 1H), 3.99 (dd, $J 5.4,7.8 \mathrm{~Hz}, 1 \mathrm{H}), 3.65$ (s, 3H), 3.57 (s, 3H), 2.41-2.37 (m, 2H), $1.61(\mathrm{~s}, 1 \mathrm{H}) .{ }^{13} \mathrm{C} \mathrm{NMR}\left(100 \mathrm{MHz}, \mathrm{CDCl}_{3}\right) \delta 197.6,131.2,126.4,112.1,74.1,53.9,52.9$, 51.9, 37.8, 35.2. IR (neat): 2986; 2951, 2844, 1728, 1603, 1440, 1390, 1335, 1278, 1252, 1188, 1121, 1096, $985 \mathrm{~cm}^{-1}$. HRMS (ESI): $\mathrm{m} / z$ calcd for $\mathrm{C}_{11} \mathrm{H}_{15} \mathrm{BrCl}_{4} \mathrm{NO}_{3}\left[\mathrm{M}+\mathrm{NH}_{4}\right]^{+} 429.8960$; found: 429.8934.

\section{2-(Bromomethyl)-2-((1S*,2R*,4S*)-1,4,5,6-tetrachloro-7,7-dimethoxybicyclo[2.2.1]hept-5-}

en-2-yl)-1,3-dioxolane 19. To a stirred solution of above obtained intermediate I (4 g, 9.68 $\mathrm{mmol})$ in toluene $(30 \mathrm{~mL})$ were added pTSA $(368.4 \mathrm{mg}, 1.93 \mathrm{mmol})$ and ethylene glycol $(1.5 \mathrm{~g}$, $24.2 \mathrm{mmol})$ at room temperature and then refluxed with Dean-Stark apparatus. After being refluxed for $48 \mathrm{~h}$, solvent was evaporated and the residue was partitioned between EtOAc (150 $\mathrm{mL})$ and water $(40 \mathrm{~mL})$, organic phase was separated and aqueous phase was extracted with EtOAc $\left(100 \mathrm{~mL}\right.$ x 3) combined organic phase was washed with $\mathrm{NaHCO}_{3}$ solution $(45 \mathrm{~mL})$, water $(150 \mathrm{~mL})$, brine $(100 \mathrm{~mL})$, dried over $\mathrm{Na}_{2} \mathrm{SO}_{4}$ and concentrated under reduced pressure. The resulting crude was purified over silica gel column chromatography (5\% EtOAc in hexane) to give $19(3.5 \mathrm{~g}, 79 \%)$ as colorless liquid; $\mathrm{R}_{f}=0.55$ (4\% EtOAc in hexane). ${ }^{1} \mathrm{H}$ NMR (400 MHz, $\left.\mathrm{CDCl}_{3}\right) \delta 4.16-4.08(\mathrm{~m}, 1 \mathrm{H}), 4.07-3.97(\mathrm{~m}, 3 \mathrm{H}), 3.60(\mathrm{~s}, 3 \mathrm{H}), 3.54(\mathrm{~s}, 3 \mathrm{H}), 3.50(\mathrm{~d}, J 11.3 \mathrm{~Hz}, 1 \mathrm{H}$ ), 3.44 (dd, $J 4.9,9.5 \mathrm{~Hz}, 1 \mathrm{H}), 3.42$ (d, $J 11.3 \mathrm{~Hz}, 1 \mathrm{H}$ ), 2.47 (dd, $J 9.8,11.7 \mathrm{~Hz}, 1 \mathrm{H}), 1.80$ (dd, $J$ 4.9, $11.7 \mathrm{~Hz}, 1 \mathrm{H}) .{ }^{13} \mathrm{C} \mathrm{NMR}\left(100 \mathrm{MHz}, \mathrm{CDCl}_{3}\right) \delta 129.2,128.1,112.3,108.6,76.3,73.6,66.7$, 65.1, 52.7, 51.6, 49.2, 38.5, 35.1. IR (neat): 2983; 2951, 2898, 1732, 1605, 1448, 1393, 1335, 1278, 1190, 1119, 1044, $989 \mathrm{~cm}^{-1}$; HRMS (APCI): $\mathrm{m} / z$ calcd for $\mathrm{C}_{13} \mathrm{H}_{15} \mathrm{BrCl}_{4} \mathrm{O}_{3} \mathrm{Na}[\mathrm{M}+\mathrm{Na}]^{+}$ 476.8806; found: 476.8805 .

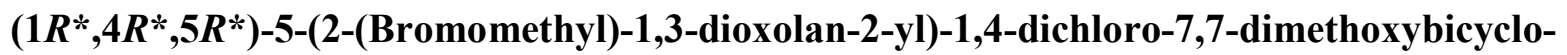

[2.2.1]heptane-2,3-dione 17. To a stirred solution of $19(3 \mathrm{~g}, 6.56 \mathrm{mmol})$ in acetonitrile $(79 \mathrm{~mL})$ were added sodium periodate (2.3 g, $10.50 \mathrm{mmol}), \mathrm{Ru}-\mathrm{LDH}$ (262 mg), $\mathrm{NaHCO}_{3}(1.65 \mathrm{~g}, 19.68$ 
mmol) and then water $(13.1 \mathrm{~mL})$ at $0{ }^{\circ} \mathrm{C}$. After being stirred for $4 \mathrm{~h}, 6 \mathrm{~mL}$ of isopropanol was added stirred for another $1 \mathrm{~h}$, then solvent was evaporated the residue was diluted with EtOAc $(100 \mathrm{~mL})$, organic phase was separated aqueous phase was extracted with EtOAc $(100 \mathrm{~mL} \times 2)$, combined organic phase was washed with $\mathrm{Na}_{2} \mathrm{~S}_{2} \mathrm{O}_{3}$ solution $(50 \mathrm{~mL} \times 2)$, water $(100 \mathrm{~mL})$, brine $(50 \mathrm{~mL})$ dried over $\mathrm{Na}_{2} \mathrm{SO}_{4}$ and concentrated under reduced pressure. The resulting crude was purified over silica gel column chromatography (15\% EtOAc in hexane) to afford 17 (2.52 g, 92\%) as yellow colored solid (needles- crystallized from $\mathrm{CH}_{2} \mathrm{Cl}_{2}$ : Hexane (1:5)); mp: 96-98 ${ }^{\circ} \mathrm{C}$; $\mathrm{R}_{f}=0.5$ (15\% EtOAc in hexane). ${ }^{1} \mathrm{H}$ NMR $\left(400 \mathrm{MHz}, \mathrm{CDCl}_{3}\right) \delta 4.11-4.04(\mathrm{~m}, 2 \mathrm{H}), 4.00-3.93$ (m, $1 \mathrm{H}), 3.76-3.69(\mathrm{~m}, 1 \mathrm{H}), 3.73(\mathrm{~s}, 3 \mathrm{H}), 3.60-3.54(\mathrm{~m}, 1 \mathrm{H}), 3.55(\mathrm{~s}, 3 \mathrm{H}), 3.35$ (dd, $J 11.3,18.5 \mathrm{~Hz}$, 2H), 2.78-2.68 (m, $1 \mathrm{H}), 2.11(\mathrm{dd}, J 4.4,12.7 \mathrm{~Hz}, 1 \mathrm{H}) .{ }^{13} \mathrm{C} \mathrm{NMR}\left(100 \mathrm{MHz}, \mathrm{CDCl}_{3}\right) \delta 188.3$, $186.5,108.7,102.4,77.1,74.0,66.4,65.1,52.8,52.3,48.3,33.8,32.9$. IR (neat) 2955, 2918, 2850, 1772, 1453, 1330, 1294, 1197, 1119, $1053 \mathrm{~cm}^{-1}$; HRMS (ESI): $\mathrm{m} / z$ calcd for $\mathrm{C}_{13} \mathrm{H}_{16} \mathrm{BrCl}_{2} \mathrm{NO}_{6}\left[\mathrm{M}+\mathrm{NH}_{4}\right]^{+}$473.9222; found 473.9199.

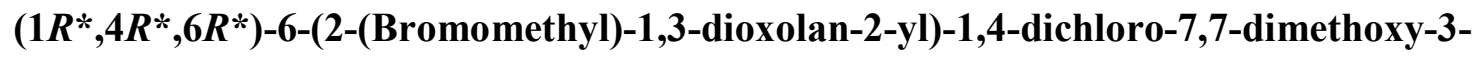
ethylenebicyclo[2.2.1] heptan-2-one 16. To a stirred suspension of methyltriphenylphosphonium bromide $(3.07 \mathrm{~g}, 8.61 \mathrm{mmol})$ in THF $(25 \mathrm{~mL})$ was added potassium tert-butoxide $(900 \mathrm{mg}, 8.03$ $\mathrm{mmol}$ ) at $0{ }^{\circ} \mathrm{C}$ and then allowed to warm to room temperature and stirred. After being stirred at $\mathrm{rt}$ for $2 \mathrm{~h}$ the resulting ylied was cooled to $-78{ }^{\circ} \mathrm{C}$ and a solution of $\mathbf{1 7}(2.4 \mathrm{~g}, 5.74 \mathrm{mmol})$ in THF (8 $\mathrm{mL}$ ) was added. After being stirred for $30 \mathrm{~min}$ (monitored by TLC), $10 \mathrm{~mL}$ of water was added slowly drop wise. The reaction mixture was diluted with EtOAc $(75 \mathrm{~mL})$, organic phase was separated, aqueous phase was extracted with EtOAc $(75 \mathrm{~mL} \times 3)$ combined organic phase was washed with water $(100 \mathrm{~mL})$, brine $(50 \mathrm{~mL})$, dried over $\mathrm{Na}_{2} \mathrm{SO}_{4}$ and concentrated under reduced pressure. The resulting crude was purified over silica gel column chromatography (12\% EtOAc in hexane) to afford $17(2.3 \mathrm{~g}, 97 \%)$ as a colorless solid (needles: crystallized from acetonitrile); mp: 80-82 ${ }^{\circ} \mathrm{C} ; \mathrm{R}_{f}=0.6\left(15 \%\right.$ EtOAc in hexane). ${ }^{1} \mathrm{H}$ NMR $\left(400 \mathrm{MHz}, \mathrm{CDCl}_{3}\right) \delta 6.18(\mathrm{~s}, 1 \mathrm{H})$, $5.67(\mathrm{~s}, 1 \mathrm{H}), 4.15-4.02(\mathrm{~m}, 2 \mathrm{H}), 3.97(\mathrm{q}, J 7.3 \mathrm{~Hz}, 1 \mathrm{H}), 3.86-3.78(\mathrm{~m}, 1 \mathrm{H}), 3.69(\mathrm{~s}, 3 \mathrm{H}), 3.50$ (s, $3 \mathrm{H}), 3.42-3.31(\mathrm{~m}, 3 \mathrm{H}), 2.74(\mathrm{t}, J 12.0 \mathrm{~Hz}, 1 \mathrm{H}), 2.01(\mathrm{dd}, J 4.9,11.7 \mathrm{~Hz}, 1 \mathrm{H}) .{ }^{13} \mathrm{C}$ NMR $(100$ $\left.\mathrm{MHz}, \mathrm{CDCl}_{3}\right) \delta 188.7,146.1,116.0,108.6,105.1,78.0,69.4,66.5,65.6,52.2,51.8,46.3,39.4$, 34.8. IR (neat) 2982, 2953, 2904, 2844, 1755, 1660, 1450, 1395, 1295, 1208, 1169, 1112, 1058, $1020 \mathrm{~cm}^{-1}$; HRMS (ESI): $m / z$ calcd for $\mathrm{C}_{14} \mathrm{H}_{21} \mathrm{BrCl}_{2} \mathrm{NO}_{5}$ [M $\left.+\mathrm{NH}_{4}\right]^{+} 433.9960$; found: 433.9951 .

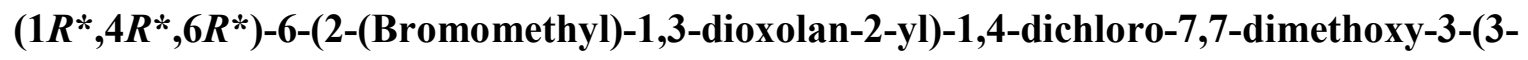
oxobutyl)bicyclo[2.2.1] heptan-2-one 20. To a stirred solution of $\mathbf{1 6}$ (2 g, $4.8 \mathrm{mmol})$ in acetone $(30 \mathrm{~mL})$ was added $2 \mathrm{~N} \mathrm{NaOH}_{\mathrm{aq}}(2.9 \mathrm{~mL}, 5.8 \mathrm{mmol})$ at $0{ }^{\circ} \mathrm{C}$. After being stirred for $2 \mathrm{~h}, 2 \mathrm{~mL}$ of $10 \% \mathrm{HCl}$ was added, diluted with EtOAc $(70 \mathrm{~mL})$, organic phase was separated, aqueous phase was extracted with EtOAc ( $80 \mathrm{~mL}$ x 3$)$ combined organic phase was washed with water (100 $\mathrm{mL})$, brine $(50 \mathrm{~mL})$, dried over $\mathrm{Na}_{2} \mathrm{SO}_{4}$ and evaporated under reduced pressure. The resulting crude was purified over silica gel column chromatography (20\% EtOAc in hexane) to give 20 $(2.23 \mathrm{~g}, 98 \%)$ as a colorless solid (needles: crystallized from acetonitrile); mp: $70-72{ }^{\circ} \mathrm{C} ; \mathrm{R}_{f}=0.5$ (20\% EtOAc in hexane). 
NMR data for major isomer. ${ }^{1} \mathrm{H}$ NMR $\left(400 \mathrm{MHz}, \mathrm{CDCl}_{3}\right)$ 84.17-4.09 (m, 1H), 4.08-4.02 (m, $1 \mathrm{H}), 3.97$ (q, J 7.3 Hz, 1H), 3.84-3.75 (m, 1H), $3.68(\mathrm{~s}, 3 \mathrm{H}), 3.59(\mathrm{~s}, 3 \mathrm{H}), 3.38(\mathrm{~d}, J 3.4 \mathrm{~Hz}, 2 \mathrm{H})$, 3.29 (dd, $J$ 5.1, $12.0 \mathrm{~Hz}, 1 \mathrm{H}), 2.98-2.84(\mathrm{~m}, 1 \mathrm{H}), 2.84-2.72(\mathrm{~m}, 2 \mathrm{H}), 2.50(\mathrm{dt}, J 2.4,12.5 \mathrm{~Hz}$, $1 \mathrm{H}), 2.21(\mathrm{~d}, J 5.4 \mathrm{~Hz}, 1 \mathrm{H}), 2.18(\mathrm{~s}, 3 \mathrm{H}), 2.12-1.86(\mathrm{~m}, 2 \mathrm{H}) .{ }^{13} \mathrm{C} \mathrm{NMR}\left(100 \mathrm{MHz}, \mathrm{CDCl}_{3}\right) \delta$ 207.9, 201.4, 108.6, 104.9, 78.4, 68.4, 66.1, 65.4, 55.4, 51.8, 46.4, 41.4, 34.8, 33.4, 30.1, 18.3;

NMR data for minor isomer: ${ }^{1} \mathrm{H}$ NMR $\left(400 \mathrm{MHz}, \mathrm{CDCl}_{3}\right) \delta 4.17-4.09(\mathrm{~m}, 1 \mathrm{H}), 4.08-4.02(\mathrm{~m}$, 2H), 3.97 (q, J 7.3 Hz, 1H), 3.84-3.75 (m, 1H), $3.66(\mathrm{~s}, 3 \mathrm{H}), 3.57$ (s, 3H), 3.38 (d, J $3.4 \mathrm{~Hz}, 1 \mathrm{H})$, $3.29(\mathrm{dd}, J 5.1,12.0 \mathrm{~Hz}, 1 \mathrm{H}), 2.98-2.84(\mathrm{~m}, 1 \mathrm{H}), 2.84-2.72(\mathrm{~m}, 2 \mathrm{H}), 2.63-2.59(\mathrm{~m}, 1 \mathrm{H}), 2.22-$ $2.18(\mathrm{~m}, 1 \mathrm{H}), 2.17(\mathrm{~s}, 3 \mathrm{H}), 2.12-1.86(\mathrm{~m}, 2 \mathrm{H}) .{ }^{13} \mathrm{C} \mathrm{NMR}\left(100 \mathrm{MHz}, \mathrm{CDCl}_{3}\right) \delta 208.1,201.9$, 108.7, 105.3, 77.8, 69.1, 66.3, 65.6, 56.7, 53.7, 51.8, 45.3, 42.4, 41.0, 34.6, 30.0, 23.4. IR (neat) 2953, 2906, 2846, 1765, 1713, 1452, 1364, 1203, 1108, 1049, $979 \mathrm{~cm}^{-1}$; HRMS (ESI): $\mathrm{m} / z$ calcd for $\mathrm{C}_{17} \mathrm{H}_{24} \mathrm{BrCl}_{2} \mathrm{O}_{6}[\mathrm{M}+\mathrm{H}]^{+}$475.0113; found: 475.0088 .

Twist-brendane 15. To a stirred solution of $20(2 \mathrm{~g}, 4.21 \mathrm{mmol})$ in THF (42 $\mathrm{mL})$ was added $\mathrm{NaH}\left(220 \mathrm{mg}, 5.48 \mathrm{mmol}, 60 \%\right.$ in mineral oil) at $0{ }^{\circ} \mathrm{C}$ and slowly allowed to warm to room temperature and then heated at $60{ }^{\circ} \mathrm{C}$. After being heated for $5 \mathrm{~h}$, reaction mixture was cooled to $0{ }^{\circ} \mathrm{C}$ and added $10 \mathrm{~mL}$ of water drop wise, solvent was evaporated. The resulting residue was diluted with EtOAc $(75 \mathrm{~mL})$, organic phase was separated aqueous phase was extracted with EtOAc $(80 \mathrm{~mL} \times 3)$, combined organic phase was washed with water $(70 \mathrm{~mL})$, brine $(40 \mathrm{~mL})$, dried over $\mathrm{Na}_{2} \mathrm{SO}_{4}$ and concentrated under reduced pressure. The resulting crude was purified over silica gel column chromatography (25\% EtOAc in hexane) to give $15(1.49 \mathrm{~g}, 90 \%)$ as a colorless solid (needles: crystallized from acetonitrile); mp: $152-154{ }^{\circ} \mathrm{C} ; \mathrm{R}_{f}=0.5(25 \%$ EtOAc in hexane). ${ }^{1} \mathrm{H}$ NMR (400 MHz, $\left.\mathrm{CDCl}_{3}\right) \delta$ 4.02-3.89 (m, 3H), 3.85-3.77 (m, $\left.1 \mathrm{H}\right), 3.60(\mathrm{~s}, 3 \mathrm{H}), 3.42$ (s, 3H), 2.80-2.69 (m, 2H), 2.66 (dd, J 5.1, $11.0 \mathrm{~Hz}, 1 \mathrm{H}), 2.53$ (d, J 7.3 Hz, 1H), 2.49 (d, J 14.2 $\mathrm{Hz}, 1 \mathrm{H}), 2.17$ (d, J $11.7 \mathrm{~Hz}, 1 \mathrm{H}), 2.14(\mathrm{~s}, 3 \mathrm{H}), 2.08$ (dd, $J 5.1,10.8 \mathrm{~Hz}, 1 \mathrm{H}), 1.96$ (dd, $J$ 4.9, 10.8 $\mathrm{Hz}, 1 \mathrm{H}), 1.81(\mathrm{dd}, J 1,14.2 \mathrm{~Hz}, 1 \mathrm{H}) .{ }^{13} \mathrm{C} \mathrm{NMR}\left(100 \mathrm{MHz}, \mathrm{CDCl}_{3}\right) \delta 208.1,201.5,108.1,104.3$, $74.2,73.3,65.3,64.4,55.0,54.6,51.6,51.2,42.4,38.9,35.6,29.9,24.3$. IR (neat) 2984, 2950, 2848, 1783, 1713, 1441, 1335, 1192, 1141, $1080 \mathrm{~cm}^{-1}$; HRMS (ESI): $\mathrm{m} / z$ calcd for $\mathrm{C}_{17} \mathrm{H}_{23} \mathrm{Cl}_{2} \mathrm{O}_{6}$ $[\mathrm{M}+\mathrm{H}]^{+}$393.0872; found: 393.0852 .

$\left(1 R^{*}, 4 S^{*}, 5 R^{*}\right)$-Methyl 2,5-dichloro-3-oxo-4-(3-oxobutyl)spiro[bicyclo[2.2.2]octane-7,2'[1,3]dioxolane]-5-carboxylate 21. To a stirred solution of $15(500 \mathrm{mg}, 1.27 \mathrm{mmol})$ in toluene $(12 \mathrm{~mL})$ was added pTSA $(290 \mathrm{mg}, 1.52 \mathrm{mmol})$ at room temperature and then slowly warm to 80 ${ }^{\circ} \mathrm{C}$. After being stirred for $4.5 \mathrm{~h}, 2 \mathrm{~mL}$ of water was added, diluted with EtOAc (50 mL), organic phase was separated aqueous phase was extracted with EtOAc $(50 \mathrm{~mL}$ x 3), combined organic phase was washed with $\mathrm{NaHCO}_{3}(10 \mathrm{~mL})$, water $(50 \mathrm{~mL})$, brine $(40 \mathrm{~mL})$, dried over $\mathrm{Na}_{2} \mathrm{SO}_{4}$ and concentrated under reduced pressure. The resulting crude was purified over silica gel column chromatography (30\% EtOAc in hexane) to give $\mathbf{2 5}$ (424 mg, 88\%) as a colorless liquid in 45:55 (exo:endo) ratio; $\mathrm{R}_{f}=0.5$ (25\% EtOAc in hexane). NMR data for exo isomer $\mathbf{2 1 b}$ : ${ }^{1} \mathrm{H}$ NMR (400 $\left.\mathrm{MHz}, \mathrm{CDCl}_{3}\right) \delta 4.54(\mathrm{~d}, J 3.4 \mathrm{~Hz}, 1 \mathrm{H}), 4.12-3.91(\mathrm{~m}, 4 \mathrm{H}), 3.85(\mathrm{~s}, 3 \mathrm{H}), 3.14-3.10(\mathrm{~m}, 1 \mathrm{H}), 3.07$ $(\mathrm{dd}, J 2.7,7.1 \mathrm{~Hz}, 1 \mathrm{H}), 2.72-2.45(\mathrm{~m}, 3 \mathrm{H}), 2.45-2.22(\mathrm{~m}, 2 \mathrm{H}), 2.16(\mathrm{~s}, 3 \mathrm{H}), 2.05-1.87(\mathrm{~m}, 1 \mathrm{H})$, 1.87-1.76 (m, 1H). ${ }^{13} \mathrm{C}$ NMR (100 MHz, $\left.\mathrm{CDCl}_{3}\right) \delta 206.5,203.2,170.8,106.8,70.8$ (2C), 65.2, 
58.1, 54.6, 54.5, 51.2, 39.7, 38.1, 38.0, 30.0, 22.5. NMR data for endo isomer $21 \mathrm{a}:{ }^{1} \mathrm{H}$ NMR (400 $\left.\mathrm{MHz}, \mathrm{CDCl}_{3}\right) \delta 4.50(\mathrm{t}, J 2.4 \mathrm{~Hz}, 1 \mathrm{H}), 4.12-3.90(\mathrm{~m}, 4 \mathrm{H}), 3.78(\mathrm{~s}, 3 \mathrm{H}), 3.14-3.03(\mathrm{dd}, J 2.4,7.3$ $\mathrm{Hz}, 1 \mathrm{H}), 2.77-2.62(\mathrm{~m}, 3 \mathrm{H}), 2.61-2.46(\mathrm{~m}, 1 \mathrm{H}), 2.41-2.21(\mathrm{~m}, 2 \mathrm{H}), 2.12(\mathrm{~s}, 3 \mathrm{H}), 2.05-1.87(\mathrm{~m}$, $1 \mathrm{H}), 1.86-1.76(\mathrm{~m}, 1 \mathrm{H}) .{ }^{13} \mathrm{C} \mathrm{NMR}\left(100 \mathrm{MHz}, \mathrm{CDCl}_{3}\right) \delta 207.2,203.0,170.4,106.8,72.1(2 \mathrm{C})$, 64.4, 56.2, 55.3, 53.7, 43.9, 42.3, 38.1, 38.0, 34.8, 29.9, 22.6; IR (neat) 2955, 1745, 1726, 1435, $1355,1281,1245,1164,1110 \mathrm{~cm}^{-1}$; HRMS (ESI): $\mathrm{m} / z$ calcd for $\mathrm{C}_{16} \mathrm{H}_{21} \mathrm{Cl}_{2} \mathrm{O}_{6}[\mathrm{M}+\mathrm{H}]^{+} 379.0715$; found: 379.0695 .

$\left(1 S^{*}, 3 S^{*}, 4 R^{*}\right)$-Methyl 5-oxo-4-(3-oxobutyl)spiro[bicyclo[2.2.2]octane-7,2'-[1,3]dioxolane]-3carboxylate 14. To a stirred solution of mixture $21(500 \mathrm{mg}, 1.32 \mathrm{mmol})$ in acetic acid $(10 \mathrm{~mL})$ was added zinc dust $(517 \mathrm{mg}, 7.9 \mathrm{mmol})$ at room temperature. After being stirred for $6.5 \mathrm{~h}$, reaction mixture was filtered washed with EtOAc $(200 \mathrm{~mL})$ filtrate was washed with $\mathrm{NaHCO}_{3}$ $(60 \mathrm{~mL})$, organic phase separated, aqueous phase was extracted with EtOAc $(100 \mathrm{~mL} \times 2)$, combined organic phase was washed with water $(100 \mathrm{~mL})$, brine $(50 \mathrm{~mL})$, dried over $\mathrm{Na}_{2} \mathrm{SO}_{4}$ and concentrated under reduced pressure. The resulting crude was purified over silica gel column chromatography (40\% EtOAc in hexane) to give 14 (348 mg, 85\%) as a colorless liquid; $\mathrm{R}_{f}=0.4$ (45\% EtOAc in hexane). ${ }^{1} \mathrm{H}$ NMR (400 MHz, $\left.\mathrm{CDCl}_{3}\right) \delta 3.98-3.93(\mathrm{~m}, 2 \mathrm{H}), 3.93-3.86(\mathrm{~m}, 2 \mathrm{H})$, $3.72(\mathrm{~d}, J 4.9 \mathrm{~Hz}, 1 \mathrm{H}), 3.65(\mathrm{~s}, 3 \mathrm{H}), 2.83(\mathrm{dd}, J 5.6,11.0 \mathrm{~Hz}, 1 \mathrm{H}), 2.59-2.54(\mathrm{~m}, 1 \mathrm{H}), 2.54-2.47$ (m, 1H), 2.45-2.38 (m, 2H), 2.38-2.34 (m, 1H), 2.21-2.14 (m, 2H), $2.13(\mathrm{~s}, 3 \mathrm{H}), 1.92-1.87(\mathrm{~m}$, $1 \mathrm{H}), 1.85-1.74(\mathrm{~m}, 1 \mathrm{H}), 1.54(\mathrm{ddd}, J 5.1,10.3,14.9 \mathrm{~Hz}, 1 \mathrm{H}) ;{ }^{13} \mathrm{C} \mathrm{NMR}\left(100 \mathrm{MHz}, \mathrm{CDCl}_{3}\right) \delta$ 211.1, 208.0, 174.9, 108.7, 64.6, 64.3, 52.1, 49.2, 45.3, 42.3, 39.8, 38.0, 35.3, 29.8, 26.2, 25.1. IR (neat) 2951, 1728, 1665, 1441, 1362, 1339, 1260, 1196, $1170 \mathrm{~cm}^{-1}$; HRMS (ESI): $\mathrm{m} / z$ calcd for $\mathrm{C}_{16} \mathrm{H}_{26} \mathrm{NO}_{6}\left[\mathrm{M}+\mathrm{NH}_{4}\right]^{+}$328.1760; found: 328.1733

Enone 22. To a stirred solution of 14 (300 mg, 0.967) in $\mathrm{MeOH}(43 \mathrm{~mL})$ was added $\mathrm{NaOH}(271$ $\mathrm{mg}, 6.77 \mathrm{mmol}$ ) and slowly warmed to reflux temperature. After being refluxed for $12 \mathrm{~h}$, solvent was evaporated under reduced pressure, residue was diluted with EtOAc $(50 \mathrm{~mL})$, organic phase was separated, aqueous phase was extracted with EtOAc $(40 \mathrm{~mL} \times 3)$ combined organic phase was washed with dil. $\mathrm{HCl}(20 \mathrm{~mL})$, water $\left(50 \mathrm{~mL}\right.$ x 2), brine $(40 \mathrm{~mL})$, dried over $\mathrm{Na}_{2} \mathrm{SO}_{4}$ and concentrated under reduced pressure. The resulting crude was dissolved in $\mathrm{MeOH}(15 \mathrm{~mL})$ cooled to $0{ }^{\circ} \mathrm{C}$, solution of $\mathrm{CH}_{2} \mathrm{~N}_{2}$ in ether was added till yellow color persist..A pinch $\mathrm{AcOH}$ was added to quench excess of diazomethane. Reaction mixture was concentrated under reduced pressure, the resulting residue was purified over silica gel column chromatography (25\% EtOAc in hexane) afforded enone 22 (220 mg, 78\%, exo/endo: 4:1) as a colorless liquid. $\mathrm{R}_{f}=0.5(50 \%$ EtOAc in hexane). NMR data for exo isomer: ${ }^{1} \mathrm{H}$ NMR $\left(400 \mathrm{MHz}, \mathrm{CDCl}_{3}\right) \delta 5.96(\mathrm{~s}, 1 \mathrm{H}), 3.98$ $3.94(\mathrm{~m}, 2 \mathrm{H}), 3.92-3.86(\mathrm{~m}, 2 \mathrm{H}), 3.66(\mathrm{~s}, 3 \mathrm{H}), 2.73-2.65(\mathrm{~m}, 2 \mathrm{H}), 2.41-2.30(\mathrm{~m}, 2 \mathrm{H}), 2.29-2.22$ (m, 1H), 2.21-2.15 (m, 1H), 2.07-1.97 (m, 2H), 1.89-1.79 (m, 2H), 1.74 (ddd, J 5.9, 8.1, $13.9 \mathrm{~Hz}$, 1H). ${ }^{13} \mathrm{C}$ NMR $\left(100 \mathrm{MHz}, \mathrm{CDCl}_{3}\right) \delta 197.5,175.1,164.7,125.9,109.4,64.3(2 \mathrm{C}), 52.0,47.1$, 46.4, 39.3, 33.6, 33.5, 31.7, 30.1, 26.3. NMR data for endo isomer: ${ }^{1} \mathrm{H} \mathrm{NMR}\left(400 \mathrm{MHz}, \mathrm{CDCl}_{3}\right)$ $\delta 5.90(\mathrm{~s}, 1 \mathrm{H}), 3.98-3.94(\mathrm{~m}, 2 \mathrm{H}), 3.92-3.86(\mathrm{~m}, 2 \mathrm{H}), 3.71(\mathrm{~s}, 3 \mathrm{H}), 2.73-2.65(\mathrm{~m}, 2 \mathrm{H}), 2.41-2.30$ $(\mathrm{m}, 2 \mathrm{H}), 2.29-2.22(\mathrm{~m}, 1 \mathrm{H}), 2.21-2.15(\mathrm{~m}, 1 \mathrm{H}), 2.07-1.97(\mathrm{~m}, 2 \mathrm{H}), 1.89-1.79(\mathrm{~m}, 2 \mathrm{H}), 1.74$ (ddd, $J$ 5.9, 8.1, $13.9 \mathrm{~Hz}, 1 \mathrm{H}) .{ }^{13} \mathrm{C} \mathrm{NMR}\left(100 \mathrm{MHz}, \mathrm{CDCl}_{3}\right) \delta 197.7,173.9,165.9,124.4,109.2,64.3$ 
(2C), 51.8, 45.3, 42.8, 38.9, 35.3, 34.4, 31.2, 29.5, 26.2. HRMS (ESI): $m / z$ calcd for $\mathrm{C}_{16} \mathrm{H}_{20} \mathrm{O}_{6} \mathrm{Na}$ $[\mathrm{M}+\mathrm{Na}]^{+}$315.1208; found: 315.1210 .

Keto ester 13. To a stirred solution of $22(190 \mathrm{mg}, 0.65 \mathrm{mmol})$ in acetone $(2 \mathrm{~mL})$ was added $6 \mathrm{~N}$ $\mathrm{HCl}(0.65 \mathrm{~mL})$ at $0{ }^{\circ} \mathrm{C}$ and allowed to warm to $\mathrm{rt}$, After being stirred for $2 \mathrm{~h}$ (monitored by tlc) reaction mixture was diluted with EtOAc $(40 \mathrm{~mL})$, organic phase was separated, aqueous phase was extracted with EtOAc $(40 \mathrm{~mL}$ x 3$)$ combined organic phase was washed with water $(50 \mathrm{~mL})$, brine $(30 \mathrm{~mL})$, dried over $\mathrm{Na}_{2} \mathrm{SO}_{4}$ and concentrated under reduced pressure. The resulting crude was purified over silica gel column chromatography (40\% EtOAc in hexane) to afford 13 (134 $\mathrm{mg}, 83 \%$, exo:endo: $4: 1$ ) as a colorless solid (needles: crystallized from acetonitrile); mp: 110$112{ }^{\circ} \mathrm{C} ; \mathrm{R}_{f}=0.4\left(50 \%\right.$ EtOAc in hexane). NMR data for exo isomer: ${ }^{1} \mathrm{H}$ NMR $(400 \mathrm{MHz}$, $\left.\mathrm{CDCl}_{3}\right) \delta 6.02(\mathrm{~d}, J 2.0 \mathrm{~Hz}, 1 \mathrm{H}), 3.72(\mathrm{~s}, 3 \mathrm{H}), 3.09-2.98(\mathrm{~m}, 1 \mathrm{H}), 2.87-2.79(\mathrm{~m}, 1 \mathrm{H}), 2.79-2.70$ (m, 1H), 2.70-2.60 (m, 1H), 2.52-2.45 (m, 1H), 2.44-2.43 (m, 1H), 2.36-2.34 (m, 1H), 2.33-2.05 $(\mathrm{m}, 4 \mathrm{H}), 1.98-1.80(\mathrm{~m}, 1 \mathrm{H}) .{ }^{13} \mathrm{C}\left(100 \mathrm{MHz}, \mathrm{CDCl}_{3}\right) \delta 210.9,196.7,174.3,161.1,126.9,52.4$, 48.4, 46.5, 42.3, 40.8, 33.4, 32.4, 29.8, 27.5. NMR data for endo isomer: ${ }^{1} \mathrm{H}$ NMR (400 MHz, $\left.\mathrm{CDCl}_{3}\right) \delta 5.98(\mathrm{~d}, J 2.0 \mathrm{~Hz}, 1 \mathrm{H}), 3.75(\mathrm{~m}, 3 \mathrm{H}), 3.09-2.98(\mathrm{~m}, 1 \mathrm{H}), 2.87-2.79(\mathrm{~m}, 1 \mathrm{H}), 2.79-2.70$ (m, 1H), 2.70-2.60 (m, 1H), 2.52-2.34 (m, 3H), 2.33-2.05 (m, 4H), 1.98-1.80 (m, 1H). ${ }^{13} \mathrm{C}$ NMR $\left(100 \mathrm{MHz}, \mathrm{CDCl}_{3}\right) \delta 210.9,196.7,174.3,161.1,125.7,50.7,45.6,43.7,42.9,42.7,42.4,40.8$, 27.9, 33.3, 29.3, 27.3. IR (neat): 2952, 1725, 1665, 1450, 1434, 1361, 1336, 1258, 1220, 1196, $1167,1029 \mathrm{~cm}^{-1}$; HRMS (ESI): $\mathrm{m} / z$ calcd for $\mathrm{C}_{14} \mathrm{H}_{20} \mathrm{NO}_{4}\left[\mathrm{M}+\mathrm{NH}_{4}\right]^{+}$266.1392; found: 266.1386 .

Enone 12. To a stirred suspension of methyltriphenylphosphonium bromide $(237 \mathrm{mg}, 0.66$ mmol) in THF ( $3 \mathrm{~mL})$ was added potassium tert-butoxide $(69 \mathrm{mg}, 0.61 \mathrm{mmol})$ at $0{ }^{\circ} \mathrm{C}$ and then allowed to warm to room temperature and stirred for $2 \mathrm{~h}$. A solution of $\mathbf{1 3}(110 \mathrm{mg}, 0.44 \mathrm{mmol})$ in THF $(1.5 \mathrm{~mL})$ was added at $-78{ }^{\circ} \mathrm{C}$ and after being stirred for $1 \mathrm{~h}, 1 \mathrm{~mL}$ of water was added slowly drop wise. The reaction mixture was diluted with EtOAc $(25 \mathrm{~mL})$, organic phase was separated aqueous phase was extracted with EtOAc $(25 \mathrm{~mL}$ x 3$)$ combined organic phase was washed with water $(30 \mathrm{~mL})$, brine $(20 \mathrm{~mL})$, dried over $\mathrm{Na}_{2} \mathrm{SO}_{4}$ and concentrated under reduced pressure. The resulting crude was purified over silica gel column chromatography $(25 \%$ EtOAc in hexane) to afford $12(78 \mathrm{mg}, 72 \%$, exo/endo: $10: 1)$ as a colorless liquid. $\mathrm{R}_{f}=0.5(30 \%$ EtOAc in hexane). ${ }^{1} \mathrm{H}$ NMR $\left(400 \mathrm{MHz}, \mathrm{CDCl}_{3}\right) \delta 5.95-5.91(\mathrm{~m}, 1 \mathrm{H}), 4.97-4.87(\mathrm{~m}, 1 \mathrm{H}), 4.72(\mathrm{~s}, 1 \mathrm{H})$, $3.67(\mathrm{~s}, 3 \mathrm{H}), 2.86-2.77(\mathrm{~m}, 1 \mathrm{H}), 2.70(\mathrm{dd}, J 5.9,10.3 \mathrm{~Hz}, 1 \mathrm{H}), 2.60-2.52(\mathrm{~m}, 3 \mathrm{H}), 2.42-2.32(\mathrm{~m}$, 2H), 2.25-2.16 (m, 1H), 2.11-1.92 (m, 3H), $1.78(\mathrm{ddd}, J 5.9,7.6,13.9 \mathrm{~Hz}, 1 \mathrm{H}) .{ }^{13} \mathrm{C}$ NMR $(100$ $\left.\mathrm{MHz}, \mathrm{CDCl}_{3}\right) \delta 197.6,175.1,166.1,147.1,126.0,107.8,52.0,47.4,40.8,39.1,36.2,35.8,33.7$, 30.9, 30.1. IR (neat): 2924, 2856, 1730, 1668, 1449, 1434, 1354, 1334, 1232, 1194, 1166, 1044 $\mathrm{cm}^{-1}$; IR (neat): 2924, 2856, 1730, 1668, 1449, 1434, 1354, 1334, 1232, 1194, 1166, $1044 \mathrm{~cm}^{-1}$; HRMS (ESI): $m / z$ calcd for $\mathrm{C}_{15} \mathrm{H}_{19} \mathrm{O}_{3}[\mathrm{M}+\mathrm{H}]^{+} 247.1334$; found: 247.1318 . 


\section{Acknowledgements}

F.A.K gratefully acknowledges CSIR-India for the financial support. B.M.B. thanks CSIR-India for a fellowship.

\section{References}

1. Kim, D. Synlett 2014, 25, 33. http://dx.doi.org/ 10.1055/s-0033-1340050.

2. Kim, D.; Ahn, S. K.; Bae, H.; Choi, W. J.; Kim, H. S. Tetrahedron Lett. 1997, 38, 4437. http://dx.doi.org/10.1016/S0040-4039(97)00925-8.

3. Kim, D.; Kim, I. H. Tetrahedron Lett. 1997, 38, 415. http://dx.doi.org/10.1016/S0040-4039(96)02313-1.

4. Kim, D.; Lim, J. I.; Shin, K. J.; Kim, H. S. Tetrahedron Lett. 1993, 34, 6557. http://dx.doi.org/10.1016/0040-4039(93)88103-P .

5. Naemura, K.; Nakazaki, M. Bull. Chem. Soc. Jpn. 1973, 46, 888. http://dx.doi.org/10.1246/bcsj.46.888.

6. Nakazaki, M.; Naemura, K.; Harita. S. Bull. Chem. Soc. Jpn. 1975, 48, 1907. http://dx.doi.org/10.1246/bcsj.48.1907.

7. Sauers, R. R.; Whittle, J. A. J. Org. Chem.1969, 34, 3579. http://dx.doi.org/10.1021/jo01263a077.

8. Vogt, B. R. Tetrahedron Lett. 1968, 9, 1579. http://dx.doi.org/10.1016/S0040-4039(01)99006-9.

9. Prantz, K.; Mulzer, J. Chem. Rev. 2010, 110, 3741-3766. http://dx.doi.org/ 10.1021/cr900386h.

10. Mehta, G.; Karmakar, S.; Shital, K.; Chattopadhyay, S. K. Tetrahedron 2004, 60, 5013. http://dx.doi.org/10.1016/j.tet.2004.04.023.

11. Barluenga, J.; Alvarez-Perez, M.; Wuerth, K.; Rodriguez, F.; Fananas, F. J. Org. Lett. 2003, 5,905 . http://dx.doi.org/ 10.1021/o1034083a

12. Khan, F. A.; Choudhury, S. Eur. J. Org. Chem. 2006, 672. http://dx.doi.org/10.1002/ejoc.200500603

13. Khan, F. A.; Rao, Ch. N. J. Org. Chem. 2011, 76, 3320. http://dx.doi.org/10.1021/jo200223a.

14. Wang, J.; Kodali, S.; Lee, S. H.; Galgoci, A.; Painter, R.; Dorso, K.; Racine, F.; Motyl, M.; Hernandez, L.; Tinney, E.; Colletti, S. L.; Herath, K.; Cummings, R.; Salazar, O.; Gonzalez, I.; Basilio, A.; Vicente, F.; Genilloud, O.; Pelaez, F.; Jayasuriya, H.; Young, K.; Cully, D.; Singh, S. B. Proc. Natl. Acad. Sci. U.S.A. 2007, 104, 7612. http://dx.doi.org/10.1073/pnas.0700746104. 
15. Jayasuriya, H.; Herath, K. B.; Zhang, C.; Zink, D. L.; Basilio, A.; Genilloud, O.; Teresa Diez, M.; Vicente, F.; Gonzalez, I.; Salazar, O.; Pelaez, F.; Cummings, R.; Ha, S.; Wang, J.; Singh, S. B. Angew. Chem. Int. Ed. 2007, 46, 4684. http://dx.doi.org/ 10.1002/anie.200701058.

16. Zhang, C.; Ondeyka, J.; Herath, K.; Jayasuriya, H.; Guan, Z.; Zink, D. L.; Dietrich, L.; Burgess, B.; Ha, S. N.; Wang, J.; Singh, S. B. J. Nat. Prod. 2011, 74, 329. http://dx.doi.org/10.1021/np100635f.

17. Yoshimitsu, T.; Nojima, S.; Hashimoto, M.; Tanaka, T. Org. Lett. 2011, 13, 3698. http://dx.doi.org/10.1021/ol2013439.

18. Nicolaou, K. C.; Tria, G. S.; Edmonds, D. J. Angew. Chem., Int. Ed. 2008, 47, 1780. http://dx.doi.org/10.1002/anie.200800066.

19. Nicolaou, K. C.; Tria, G. S.; Edmonds, D. J.; Kar, M. J. Am. Chem. Soc. 2009, 131, 15909. http://dx.doi.org/10.1021/ja906801g.

20. Yun, S. Y.; Zheng, J.-C.; Lee, D. Angew. Chem. Int. Ed. 2008, 47, 6201. http://dx.doi.org/10.1002/anie.200801587.

21. Varseev, G. N.; Maier, M. E. Angew. Chem., Int. Ed. 2009, 48, 3685. http://dx.doi.org/10.1002/anie.200900447.

22. Yoshimitsu, T.; Nojima, S.; Hashimoto, M.; Tanaka, T. Org. Lett. 2011, 13, 3698. http://dx.doi.org/10.1021/ol2013439.

22. Nicolaou, K. C.; Toh, Q.-Y.; Chen, Y.-K. J. Am. Chem. Soc. 2008, 130, 11292. http://dx.doi.org/10.1021/ja804588r.

23. Austin, B.; Banwell, M. G.; Willis, A. C. Org. Lett. 2008, 10, 4465. http://dx.doi.org/10.1021/o1801647h.

24. Singh, V.; Sahu, B. C.; Bansal, V.; Mobin, S. M. Org. Biomol. Chem. 2010, 8, 4472. http://dx.doi.org/10.1039/C004316H.

25. Hayashida, J.; Rawal, V. H. Angew. Chem., Int. Ed. 2008, 47, 4373-4376. http://dx.doi.org/10.1002/anie.200800756.

26. Li, P.; Yamamoto, H. Chem. Commun. 2010, 46, 6294. http://dx.doi.org/10.1039/C0CC01619E.

27. Tiefenbacher, K.; Mulzer, J. Angew. Chem., Int. Ed. 2008, 47, 2548. http://dx.doi.org/10.1002/anie.200705303.

28. Tiefenbacher, K.; Mulzer, J. J. Org. Chem. 2009, 74, 2937. http://dx.doi.org/10.1021/j09001855.

29. Waalboer, D. C. J.; Schaapman, M. C.; van Delft, F. L.; Rutjes, F. P. J. T. Angew. Chem., Int. Ed. 2008, 47, 6576. http://dx.doi.org/10.1002/anie.200802912.

30. Ghosh, A. K.; Xi, K. Angew. Chem., Int. Ed. 2009, 48, 5372. http://dx.doi.org/10.1002/anie.200902338.

31. Hirai, S.; Nakada, M. Tetrahedron Lett. 2010, 51, 5076. http://dx.doi.org/10.1016/j.tetlet.2010.07.088. 
32. Hirai, S.; Nakada, M. Tetrahedron 2011, 67, 518.

http://dx.doi.org/10.1016/j.tet.2010.10.076.

33. Palanichamy, K.; Subrahmanyam, A. V.; Kaliappan, K. P. Org. Biomol. Chem. 2011, 9, 7877.

http://dx.doi.org/10.1039/C1OB06155K.

34. Yadav, J. S.; Goreti, R.; Pabbaraja, S.; Sridhar, B. Org. Let. 2013, 15, 3782-3785.

http://dx.doi.org/10.1021/ol401760e.

35. Barykina, O. V.; Rossi, K. L.; Rybak, M. J.; Snider, B. B.; Org. Lett. 2009, 11, 5334. http://dx.doi.org/10.1021/o1902194q.

36. Khan, F. A.; Budanur, B. M.; Sudheer, C. Chem. Eur. J. 2015, 21, 7021. http://dx.doi.org/10.1002/chem.201500131

37. Barrero, A. F.; Alvarez-Manzaneda, E. J.; Chahboun, R.; Meneses, R. Synlett 1999, 1663. http://dx.doi.org/10.1055/s-1999-2908.

38. Frigerio, M.; Santagostino, M.; Sputore, S. J. Org. Chem. 1999, 64, 4537. http://dx.doi.org/10.1021/jo9824596.

39. Nicolaou, K. C.; Zhong, Y.-L.; Baran, P. S. J. Am. Chem. Soc. 2000, 122, 7596. http://dx.doi.org/10.1021/ja001825b.

40. Palomo, C.; Oiarbide, M.; Sharma, A. K.; Gonzalez-Rego, M. C.; Linden, A.; Garcia, J. M.; Gonzalez, A. J. Org. Chem. 2000, 65, 9007. http://dx.doi.org/10.1021/jo001031f.

41. Wang, C.; Li, Z.; Ju, Y.; Koo, S. Eur. J. Org. Chem. 2012, 6976. http://dx.doi.org/10.1002/ejoc.201201194.

42. Wei, Y.; Lin, S.; Liang, F. Org. Lett. 2012, 14, 4202. http://dx.doi.org/10.1021/o1301871s.

43. Mehta, G.; Padma, S. J. Am. Chem. Soc. 1987, 109, 7230. http://dx.doi.org/10.1021/ja00257a076.

44. Kuroda, S.; Takamura, F.; Tenda, Y.; Itani, H.; Tomishima, Y.; Akahane, A.; Sakane, K. Chem. Pharm. Bull. 2001, 49, 988. http://dx.doi.org/10.1248/cpb.49.988.

45. Khan, F. A.; Prabhudas, B.; Dash, J.; Sahu, N. J. Am. Chem. Soc. 2000, 122, 9558. http://dx.doi.org/10.1021/ja001956c.

46. Khan, F. A.; Sahu, N. J. Catal. 2005, 231, 438. http://dx.doi.org/10.1016/j.jcat.2005.02.001.

47. Khan, F. A.; Sudheer, Ch. Adv. Synth. Catal. 2009, 351, 939. http://dx.doi.org/10.1002/adsc.200900042. 